\title{
Estimating the risk-return tradeoff in MENA Stock Markets
}

\author{
Salim Lahmiri*
}

ESCA School of Management, Casablanca, Morocco \& Department of Computer Science, University of Quebec at Montreal, Montreal, Canada

\section{H R O I C LE A B T R A C T}

Article history:

Received October 2, 2012

Accepted January 2, 2013

Available online

January 22013

Keywords:

MENA Stock Markets

GARCH-M

Econometrics

\begin{abstract}
This study employs the generalized autoregressive conditionally heteroskedastic in the mean (GARCH-M) methodology to investigate the return generating process of Jordan, Kingdom of Saudi Arabia (KSA), Kuwait, and Morocco stock market indices. The tradeoff between returns and the conditional variance is found to be positive in all markets. In other words, the empirical findings show that investors are rewarded for their exposure to more risk in these financial markets. This result is consistent with both financial theory and empirical finance.
\end{abstract}

\section{Introduction}

Since early works of Merton (1973, 1980), the risk-return relationship has become an important concern for investors and academicians. In equilibrium, additional risk taken by an investor should be compensated through higher expected return. As a result, risk and return are expected to be positively related. The GARCH-in-Mean (generalized autoregressive conditionally heteroskedastic in the mean: GARCH-M) of Engle et al. (1987) is the most common model to evaluate the time-varying riskreturn relationship (French et al., 1987; Campbell \& Hentschel, 1992; Bansal \& Lundblad, 2002; Girard et al., 2002; Xing \& Howe, 2003; Baillie \& DeGennaro, 1990; Glosten et al., 1993; Nam et al., 2001).

The GARCH-M model allows the introduction of the conditional variance, or some function of it, as a regressor in the mean equation. Thus, the validity of the positive relationship between risk and return can statistically be tested. The empirical literature using GARCH-M reported conflicting findings. In other words, empirical literature examining this issue is not unanimous. For instance, Baillie and DeGennaro (1990), Glosten et al. (1993), and Nam et al. (2001) have reported a negative

* Corresponding author.

E-mail addresses: slahmiri@esca.ma \& lahmiri.salim@courrier.uqam.ca (S. Lahmiri)

(c) 2013 Growing Science Ltd. All rights reserved. doi: $10.5267 /$ j.dsl.2013.01.001 
relationship between risk and return, whilst French et al. (1987), Campbell and Hentschel (1992), Bansal and Lundblad (2002), Girard et al. (2002), and Xing and Howe (2003) have reported a positive relationship.

Most of previous works examined the risk-return tradeoff in developed countries (French et al., 1987; Campbell \& Hentschel, 1992; Bansal \& Lundblad, 2002; Girard et al., 2002; Xing \& Howe, 2003; Baillie \& DeGennaro, 1990; Glosten et al., 1993; Nam et al., 2001), and a little attention has been paid to developing countries (Curci et al., 2002; Forgha, 2012). The purpose of this paper is to investigate the risk-return tradeoff in the Middle East and North Africa (MENA) most active stock markets; namely Jordan, Kingdom of Saudi Arabia (KSA), Kuwait, and Morocco. The ARMAGARCH-M (Autoregressif moving average: ARMA, see Box et al., 1994) process is employed to conduct this empirical study.

The outline of the rest of the paper is as follows. The next section briefly describes the data and the ARMA-GARCH-M model and provides the results. The concluding section summarizes the findings.

\section{Data, estimation, and results}

The data employed in this application consist of daily observations on Jordan, Kingdom of Saudi Arabia (KSA), Kuwait, and Morocco market stock market indices. The overall sample covers the period July $2^{\text {th }} 2006$ to December $22^{\text {th }} 2011$ for Jordan, January $6^{\text {th }} 2007$ to December $21^{\text {th }} 2011$ for KSA, June $17^{\text {th }} 2001$ to December $21^{\text {th }} 2011$ for Kuwait, and the period from December $8^{\text {th }} 2008$ to November 30th 2011 for Morocco. The daily continuously compounded percentage returns $\left(r_{t}\right)$ are defined as the first differences of the natural logarithmic price levels, i.e. $r_{t}=\log \left(P_{\mathrm{t}}\right)$ - $\log \left(P_{\mathrm{t}-1}\right)$ where $P$ is the closing price level of the stock market index, and $t$ is the time script. The price level and returns of each market are shown in Figures 1.a to 1.d, where the $x$-axis refers to observations.

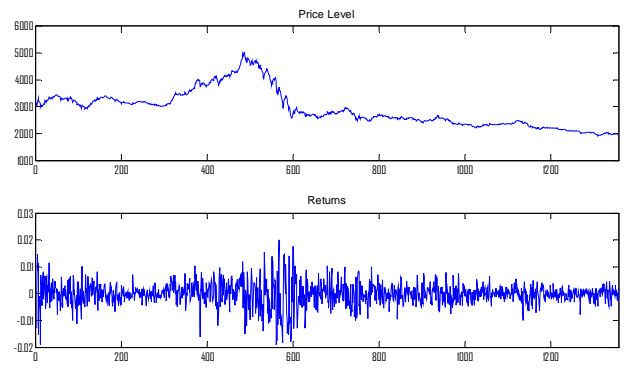

Fig. 1.a Series of Jordanian stock market price level and returns
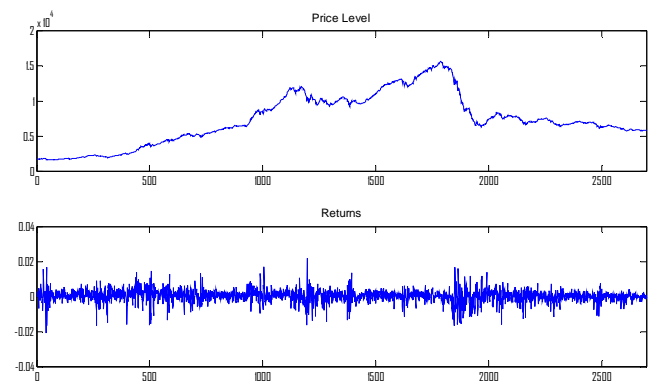

Fig. 1.c Series of Kuwaiti stock market price level and returns

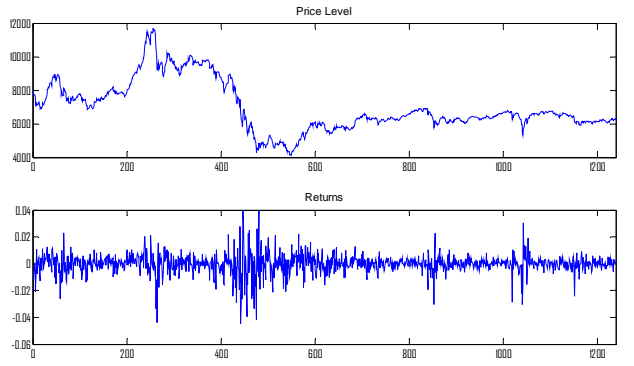

Fig. 1.b Series of Saudi stock market price level and returns

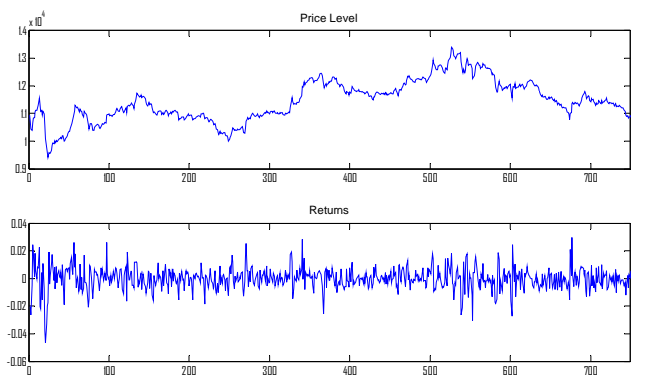

Fig. 1.d Series of Casablanca stock market price level, returns, and volatility

The descriptive statistics of return series $\left(r_{t}\right)$ are given Table 1 . In each market, the returns are found to be less volatile given the low value of standard deviation. In addition, the distribution of the returns 
series is negatively skewed in Jordan, KSA, and Kuwait. The Jarque-Bera statistic is highly statistically significant at the 5 percent significance level, indicating that the null hypothesis of normally distributed returns series is rejected in all markets. The null hypothesis of non-stationarity (unit root) of return series is tested using the Augmented Dickey Fuller (ADF) (Dickey and Fuller, 1979) and Philipps and Perron (1988) unit root tests. Both the ADF and PP show that the daily returns series of all markets follow stationary processes (See return series in Figures 1.a to 1.d). The Ljung Box-Q (LB-Q) (Ljung and Box, 1978) statistics are computed to test for serial correlation in the returns series. In all markets, the LB-Q statistics are highly statistically significant at the 5 percent level. As a result, the null hypothesis of no autocorrelation in the returns series is rejected. At first sight, all markets daily returns in Figures 1.a to 1.d show that the mean returns are constant but the variances change over time suggesting that the volatilities tend to cluster. In sum, the preliminary analysis shows that all markets daily returns exhibit means reversion and irregular time-varying volatilities. Thus, a GARCH model is motivated to accommodate the observed time-varying returns volatilities.

\section{Table 1}

Descriptive statistics of daily returns

\begin{tabular}{lcccc}
\hline Parameters & Jordan & KSA & Kuwait & Morocco \\
\hline Observations & 1239 & 2695 & 1356 & 749 \\
Mean & -0.000148 & -0.0000807 & 0.000201 & 0.00000125 \\
Median & 0.000000 & 0.000306 & 0.000253 & 0.000242 \\
Maximum & 0.020031 & 0.039466 & 0.021918 & 0.029572 \\
Minimum & -0.019100 & -0.0444856 & -0.020747 & -0.046656 \\
Std. Deviation & 0.004327 & 0.007354 & 0.003703 & 0.007985 \\
Skewness & -0.340457 & -0.801767 & -0.610262 & -0.424805 \\
Kurtosis & 5.958844 & -0.801767 & 7.237833 & 6.747769 \\
Jarque-Bera & 520.8397 & 3067.457 & 2183.950 & 460.8724 \\
& $(0.00000)$ & $(0.00000)$ & $(0.00000)$ & $(0.00000)$ \\
\hline ADF & -28.66228 & -32.29327 & -41.24640 & -20.93367 \\
PP & $(0.00000)$ & $(0.00000)$ & $(0.00000)$ & $(0.00000)$ \\
& -28.40287 & -32.28726 & -44.54808 & -20.70184 \\
\hline LB-Q (5) & $(0.00000)$ & $(0.00000)$ & $(0.0001)$ & $(0.00000)$ \\
\hline LB-Q (10) & 31.611 & 179.549 & 184.298 & 85.796 \\
LB-Q (15) & $(0.0000)$ & $(0.0000)$ & $(0.0000)$ & $(0.0000)$ \\
LB-Q (20) & 47.565 & 215.903 & 223.732 & 64.494 \\
LB-Q (25) & $(0.0000)$ & $(0.0000)$ & $(0.0000)$ & $(0.0000)$ \\
& 92.084 & 284.812 & 259.341 & $(09.963$ \\
\hline
\end{tabular}

The ARMA( $(p, q)-\mathrm{GARCH}(1,1)-\mathrm{M}$ approach is used to model the relationship between stock returns and risk. Basically, the technique consists of a mean equation (Eq.1) and a variance equation (Eq.2) described as follows:

$$
\begin{aligned}
& r_{t}=\alpha+\phi_{1} r_{t-1}+\phi_{2} r_{t-2}+\ldots+\phi_{p} r_{t-p}+\varepsilon_{t}+\pi_{1} \varepsilon_{t-1}+\pi_{2} \varepsilon_{t-2}+\ldots+\pi_{q} \varepsilon_{t-q}+\lambda \log \left(h_{t}^{2}\right), \\
& h_{t}^{2}=\omega+\beta h_{t-1}^{2}+\gamma \varepsilon_{t-1}^{2}, \\
& \varepsilon_{t} \mid \Omega_{t-1} \propto N\left(0, h_{t}\right),
\end{aligned}
$$

where, $t$ is the time script, $r$ is the stock market return, $h$ is the GARCH component, and $\varepsilon$ is a random variable that depends on the information set $\Omega$ and has a zero mean and conditional variance $h$. 
Finally, $\alpha, \phi, \pi, \lambda, \omega, \beta$, and $\gamma$ are parameters to be estimated. The volatility of the stock market returns is measured by the conditional variance $h_{t}$ described as a function of the squared values of the past residuals $\varepsilon_{t}^{2}$ reflecting the ARCH (autoregressive conditionally heteroskedastic) component and the autoregressive term $h_{t-1}$. The parameters $\beta$ and $\gamma$ must satisfy the stationarity conditions such that $\beta \geq 0, \gamma \geq 0$, and $(\beta+\gamma) \leq 1$. The later condition measures the degree of volatility persistence. Indeed, the degree of persistence is important to determine the relationship between volatility and return since only persistent volatility explains changes in risk (Devaney, 2001).

In this study, the GARCH(1,1) is chosen since it is parsimonious and allows for long memory in the volatility process (Devaney, 2001). The $\operatorname{ARMA}(p, q)-\operatorname{GARCH}(1,1)-\mathrm{M}$ model is specified based on the Akaike information criterion and Bayesian information criterion (Green, 2008). Thus, the identified model is ARMA(1,0)-GARCH(1,1)-M for Jordan, ARMA(1,1)-GARCH(1,1)-M for KSA, and ARMA(2,1)-GARCH(1,1)-M for both Kuwait and Morocco. Equations 1 and 2 are estimated using maximum likelihood routine (Green, 2008). The conditional volatility series $h_{t}$ of each market are shown in Figure 2, where the $x$-axis refers to observations.
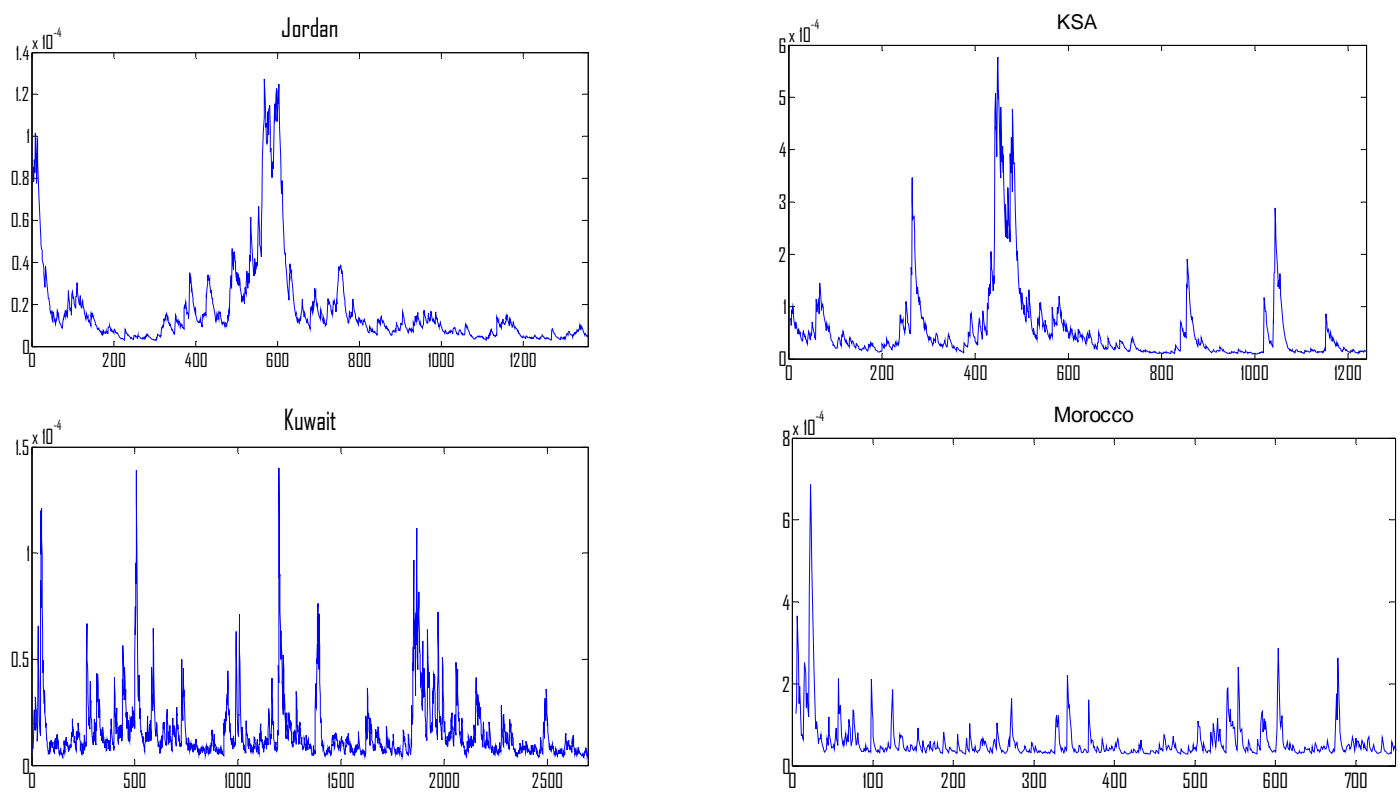

Fig. 2. Volatility series.

Table 2 shows the results of the ARMA-GARCH-M model for each market. For Jordan, it indicates that all estimates of the mean equation and variance equation are statistically highly significant at the $5 \%$ significance level, except for the constant term and the parameter $\lambda$. In particular, the latter is positive $(0.0000983)$ but not significant $(p$-value $=0.4805)$. As a result, the relationship between risk and return in Jordan stock market is positive but not significant. Similarly, for KSA stock market all estimates of the mean equation and variance equation are statistically highly significant at the $5 \%$ significance level, except for the constant term and the parameter $\lambda$. The parameter $\lambda$ is positive $(0.000216)$ but not significant $(p$-value $=0.4232)$. Thus, the relationship between return and risk in KSA equity market is positive but not significant. Finally, all estimates of the mean equation and variance equation are statistically highly significant at the $5 \%$ significance level for Kuwait and Morocco. For instance, the regression results obtained with Kuwaiti data indicate that the parameter $\lambda$ is positive (0.000263) and highly significant ( $p$-value $=0.0060)$. Similarly, the regression results obtained with Moroccan data indicate that the parameter $\lambda$ is positive (0.001694) and highly significant $(p$-value $=0.0186)$. Thus, the relationship between risk and return in both Kuwaiti and Moroccan stock markets is positive and statistically highly significant. Furthermore, the regression 
results indicate that the sum of the estimates of $\beta$ and $\gamma$ is less than unity in all markets which is consistent with theory. Finally, the GARCH effect $(\beta)$ is highly significant indicating that the stock market volatility is time-varying in all markets. In sum, the empirical findings show that the relationship between risk and return in Jordan, KSA, Kowait, and Morocco is positive and consistent with theory (Merton, 1973, 1980), and with French et al. (1987), Campbell and Hentschel (1992), Bansal and Lundblad (2002), Girard et al. (2002), and Xing and Howe (2003) who have reported a positive empirical relationship.

Table 2

Estimates of the $\operatorname{ARMA}(p, q)-\operatorname{GARCH}(m, n)-\mathrm{M}$ model

\begin{tabular}{|c|c|c|c|c|}
\hline Parameters & Jordan & KSA & Kuwait & Morocco \\
\hline \multicolumn{5}{|c|}{ Mean equation } \\
\hline \multirow{2}{*}{$\alpha$} & 0.001123 & 0.002655 & 0.003873 & 0.017009 \\
\hline & $(0.5014)$ & $(0.4232)$ & $(0.0020)$ & (0.0195) \\
\hline \multirow[t]{2}{*}{$\phi_{1}$} & 0.175296 & 0.730074 & 1.101524 & 0.809508 \\
\hline & $(0.0000)$ & $(0.0000)$ & $(0.0000)$ & $(0.0006)$ \\
\hline \multirow[t]{2}{*}{$\phi_{2}$} & & & -0.12481 & -0.180926 \\
\hline & & & $(0.0000)$ & $(0.0002)$ \\
\hline \multirow[t]{2}{*}{$\pi_{1}$} & & -0.641606 & -0.941891 & -0.621536 \\
\hline & & $(0.0000)$ & $(0.0000)$ & $(0.0080)$ \\
\hline \multirow[t]{2}{*}{$\lambda$} & 0.0000983 & 0.000216 & 0.000263 & 0.001694 \\
\hline & $(0.4805)$ & $(0.4232)$ & $(0.0060)$ & $(0.0186)$ \\
\hline \multicolumn{5}{|c|}{ Variance equation } \\
\hline \multirow[t]{2}{*}{$\omega$} & 0.000000185 & 0.00000101 & 0.000000326 & 0.0000133 \\
\hline & $(0.0001)$ & $(0.0000)$ & $(0.0000)$ & $(0.0000)$ \\
\hline \multirow[t]{2}{*}{$\beta$} & 0.893327 & 0.858601 & 0.8166682 & 0.524767 \\
\hline & $(0.0000)$ & $(0.0000)$ & $(0.0000)$ & $(0.0000)$ \\
\hline \multirow[t]{2}{*}{$\gamma$} & 0.092198 & 0.124921 & 0.170134 & 0.237960 \\
\hline & $(0.0000)$ & $(0.0000)$ & $(0.0000)$ & $(0.0000)$ \\
\hline$\beta+\gamma$ & 0.985525 & 0.983522 & .986802 & 0.762727 \\
\hline
\end{tabular}

\section{Conclusion}

The purpose of this empirical study is to investigate the contemporaneous relationship between risk measured by conditional volatility and returns with an ARMA-GARCH-in-Mean model in MENA most active stock markets including Jordan, KSA, Kuwait, and Morocco. Our results provide several insights. First, consistent with financial theory, the returns in all stock market are positively related to risk which is measured by market volatility. Second, the relationship between risk and returns in Kuwait and Morocco is statistically highly significant, whilst it is not significant in Jordan and KSA. Third, we found strong evidence of GARCH effect in all markets indicating a time variation in the variance of return series. In sum, the empirical findings suggest that investors are rewarded for taking more risk in these markets.

\section{References}

Baillie, R., \& DeGennaro, P. (1990). Stock return and volatility. Journal of Financial and Quantitative Analysis, 25, 203-214.

Bansal, R., \& Lundblad, C. (2002). Market efficiency, asset returns, and the size of the risk premium in global equity markets. Journal of Econometrics, 109, 195-237.

Box G.E.P., Jenkins G., \& Reinsel, G.C. (1994). Time Series Analysis: Forecasting and Control. Third edition. Prentice-Hall. 
Campbell, J.Y., \& Hentschel, L. (1992). No news is good news: an asymmetric model of changing volatility in stock. Journal of Financial Economics, 31, 281-318.

Curci, R., Grieb, T., \& Reyes, M.G. (2002). Mean and Volatility Transmission for Latin american Equity Markets. Studies in Economics and Finance, 20 (2), 39-57.

Devaney, M. (2001). Time varying risk premia for real estate investment trusts: A GARCH-M model. The Quarterly Review of Economics and Finance, 41, 335- 346.

Dickey, D. A., \& Fuller, W.A. (1979). Distribution of the Estimators for Autoregressive Time Series with a Unit Root. Journal of the American Statistical Association, 74, 427-431.

Engle, R.F., Lilien, D.M., \& Robins, R.P. (1987). Estimating time varying risk premia in the term structure: the ARCH-M model. Econometrica, 55, 391-407.

Forgha, N.G. (2012). An Investigation into the Volatility and Stock Returns Efficiency in African Stock Exchange Markets. International Review of Business Research Papers, 8 (5), 176-190.

French, K.R., Schwert, G.W., \& Stambaugh, R.F. (1987). Expected stock returns and volatility. Journal of Financial Economics, 19, 13-29.

Girard, E., Rahman, H., \& Zaher, T. (2002). Intertemporal risk return relationship in the Asian markets around the Asian crisis. Financial Services Review, 10, 249-272.

Glosten, L., Jagannatha, R., \& Runkle, D. (1993). The relationship between expected value and the volatility of the nominal excess return on stocks. Journal of Finance, 48, 1779-1801.

Green, W.H. Econometric Analysis. Seventh edition. Prentice-Hall, 2008.

Ljung, G.M., \& Box, G.E.P. (1978). On a Measure of a Lack of Fit in Time Series Models. Biometrika, 65 (2), 297-303.

Merton, R.C. (1973). An intertemporal capital asset pricing model. Econometrica, 41 (5), 867-887.

Merton, R.C. (1980). On estimating the expected return on the market. Journal of Financial Economics, 8, 323-361.

Nam, K., Pyun, C.S., \& Avard, S.L. (2001). Asymmetric reverting behavior of short horizon stock returns: an evidence of stock market overreaction. Journal of Banking and Finance, 25 (4), $807-$ 821.

Phillips, P.C.B, \& Perron, P. (1988). Testing for a Unit Root in Time Series Regression. Biometrika, 75 (2), 335-346.

Xing, X., \& Howe, J.S. (2003). The empirical relationship between risk and return: evidence from the UK stock market. International Review of Financial Analysis, 12 (3), 329-346. 